\title{
Introduction: Testing Freedom
}

This book offers an updated overview of the diverse ways freedom is understood and practised across cultural contexts, including the emergent relationships between governance, autonomy and liberty that characterise everyday worlds. Oksala (2005: 209) has argued that when understood as a practice, 'freedom is defined and gains a meaning only through the concrete operations through which its existence is tested. It emerges through the particular, political and/or personal struggles that try and test its limits, possibilities or extent'. In response, this volume mobilizes a wide range of ethnography in order to expand our understanding of the social dynamics, ontological assemblages, and referential acts by which the co-dependence of authority and freedom is re-created. In rethinking political protocol through the lens of 'freedom', we tackle a central concern: 'How are normative claims used to present a particular way to define a problem and its solution, as if these were the only ones possible, while enforcing closure and silence on other ways of thinking and talking?' (Shore and Wright 1997: 3)

Our understanding of the daily operations of freedom in practice includes, then, a strong focus on the spaces of argument and negotiation wherein daily meanings of freedom appear and are tested, and how the material apparatus of freedom is operationalized opening new limits and horizons. Thus a wealth of ethnographic insight is provided in each of our chapters on how different people, in multiple sites across the world, deploy meanings of freedom that foreclose certain possibilities for comprehending and narrating freedom while opening others up. At ground level, the relationship of governance and freedom is mercurial - sometimes the intervention of authority allows further freedom, sometimes it is that which blocks the pathway to it. However, in our view, 'governance through freedom' is not an exclusive characteristic of late-liberal regimes (Rose 1999).

Who or what can be free, or not free? To the extent that meaning is defined through reference, or acts of naming, different meanings of freedom deployed in daily life derive their significance from specific and contingent instructions that allow the particularities of freedom to be constituted. Hence, determining the meaning of freedom in daily life involves an analysis of practical power effects, as well as the struggles over which instructions, or policies, should be followed in order to determine who and what falls under the category of 'the free', and what or who should be excluded from it. Nevertheless, to address our 
question satisfactorily an exploration of the relationship between semantics and ontology cannot be neglected. Each of the contributors to this volume adds an ethnographic focus to debates surrounding a family of terms that includes 'freedom', 'liberty', 'autonomy' and 'selfdetermination'. In each case on view here we see elements of governance instantiated at the same moment that certain kinds of claim to freedom are defined and put into play. Some of the contributors give more focus to the semantics and pragmatics of freedom in language and daily life, others, choose to approach their ethnographic material as an ontological inquiry.

To get us started, we propose some considerations regarding both the semantic problems implicated in anthropological studies of 'freedom', 'liberty', 'autonomy' and 'self-determination', as well as, the ontological challenges that those who venture into the field may encounter along their path when they adopt an ethnographic approach (see, for example, Kelty in this volume).

\section{Autonomy versus freedom}

'I doubt whether any anthropologist has set out to study a people's ideas about freedom in the setting of a field situation' Audrey Richards suggests at the beginning of a discussion of Central and East African concepts of freedom from the 1960s (1963:49). Richards was right that ethnographies with this focus were rare at the time she was writing. This had not always been the case, though, before the advent of professional anthropology. European travellers of earlier eras did attend to the striking 'freedom' of the peoples they visited. For example, Chrétien Leclerq and earlier Samuel de Champlain, both highlighted this when describing the Algonkian peoples they encountered in North America during the Seventeeth Century whose 'self-reliant' and 'outspoken demeanour' impressed them considerably:

Noone ever seemed to give orders nor to take them; while each acted on his own, all could coordinate their activities and work together. Further, their own sense of intrinsic freedom of movement in and the symbiosis with their woodland environment was brought into relief in discussions with Europeans, as the Indians gradually came to understand the nature of the environment from which they had come in Europe (McFeat 1974:53). 
Freedom in Practice: Governance, Autonomy and Liberty in the Everyday

Moises Lino e Silva and Huon Wardle [PREPUBLICATION VERSION] (2016)

'Freedom' is still not a widely deployed concept in contemporary anthropology. In fact a certain implicit accusation of naivety attaches to any attempt to give 'freedom' analytical status, and part of our aim in this introduction is to debate why. However, if instead Richards had been asked to explore 'autonomy', she would have had to admit that the literature was already burgeoning, and has continued to grow. Why the difference? Is it because, rooted in ancient Greek, the word 'autonomy' has a more academic ring than its Anglo-Saxon cousin 'freedom'? Or are there subtle specificities of emphasis and meaning at issue? As we will discuss later, one problem may be that the meaning of 'freedom' is subtly entangled with Judeo-Christian controversies around 'free will' that anthropologists may hope to evade by using 'autonomy' instead. Autonomy may fit better with the anthropologist's overall emphasis on social or cultural conformity in a way that 'freedom' does not (Laidlaw 2014, Murphy C. \& J. Throop 2010).

Either way, separately, or as a package, the core tenets of autonomyfollowing one's own path and rules in life, displaying mastery over one's own condition, the desire to live independent of control by others - have been, with provisos to follow, ubiquitous in the modern ethnographic record. In contrast, 'Freedom' has appeared as a fuzzier, or sometimes overly narrow, target, seemingly harder to localise or define as Richards pointed out. As such, high valuations of autonomy are recorded in ethnographies from so many different locationsAustralasia, Africa, Asia, the American plains, Lowland Amazoniathat we may reasonably infer some kind of primary intuition about what it means to be human either on the part of the people studied, or of ethnographers, or both.

Anthropologists have witnessed this stress on autonomy especially in so-called small-scale, non-literate cultures, but also in large, state-like formations, where, even if people complain about its absence, the ideal is still ubiquitous. The principle of autonomy has been emphasized among some groups, such as the Indians of the North American Plains, almost to the point of cliché (e.g. Hoebel 1954:142-143). Clastres' argument that lowland Amazonian societies have been fundamentally shaped by their pursuit of communal autonomy 'against the state' has been profoundly influential in ethnological work in that region too. In The Nuer, Evans-Pritchard gives us perhaps the classic description of how the struggle for autonomy has a role in creating order in an otherwise 'anarchic' society. In this quote 'autonomous' is synonymous with 'free and independent': 
Freedom in Practice: Governance, Autonomy and Liberty in the Everyday

Moises Lino e Silva and Huon Wardle [PREPUBLICATION VERSION] (2016)

[A Nuer man] must always be prepared to fight, and his willingness and ability to do so are the only protection of his integrity as a free and independent person against the avarice and bullying of his kinsmen. They protect him against outsiders, but he must resist their demands on himself. The demands made on a man in the name of kinship are incessant and imperious and he resists them to the utmost.

The Nuer has a strong focus on the contest for autonomy of young Nuer men, but classic studies by Phyllis Kaberry amongst others have witnessed a similar stress amongst Aboriginal women (1939), while Fred Myers has written in depth on the pursuit of autonomy both by Pintupi women and men in Western Australia (see Diane Austin-Broos, this volume on the idea of 'living this way') and Joanna Overing has written widely on the combined emphases on individual freedom and conviviality that characterize the interdependency of Piaroa women and men in Amazonia (e.g. Overing and Passes 2000). These are all cases of mobile, broadly egalitarian societies. Without going deeper into questions about how autonomy is differentiated within these societiese.g. between male and female, younger and older-what they show generally is that ideas akin to autonomy seem to be readily available everywhere ethnographers go. The fact that this is not simply a matter of empirical observation will hopefully become clear as this discussion opens outward.

\section{The liberty of translation}

As we may begin to recognise, identifying 'freedom' or 'autonomy' as existences in their own terms is not without complication. What possible definition of freedom could one suggest based on ethnographic research methods? Before proposing any answers, it helps if we make certain 'pre-theoretical' commitments more explicit: what is the presupposed relationship between freedom, the particular languages in which fieldwork is conducted, and the problem of translation?

Notice how the following description of the Pintupi, extracted from its ethnographic context, might be understood to apply almost anywhere: 'Pintupi life is highly personalized; for people to abstract from the intimate and familiar is unusual. They place emphasis on individuals, their autonomy, and their capacity to choose courses of action' (Myers 1992:18). To take a quite different example, the Confucian concept of ziyou -if we are able momentarily to ignore radical differences of social 
scale and hierarchy-has a more than passing resemblance to those Pintupi principles. Ziyou is often glossed as 'freedom', but fits well, arguably better, with 'autonomy' since, literally, ziyou translates from Chinese as 'self-follow', a principle, in other words, of following one's own route ( $\mathrm{Li}$ 2014). As with the Pintupi, however, the kind of autonomy involved is understood to unfold out of a traditional range of values. And herein lies a problem-'autonomy' may seem to cover similar territory to 'freedom', and 'autonomy' may appear to be replayed across different social settings, but perhaps this is an illusion created by our attempts at translation.

Take a different example, the Hindi term swaraj, which is likewise often glossed as 'freedom', was coopted during the struggle for Indian independence to mean both 'self-rule' and 'home rule' (with resulting ambiguities). For Gandhi, swaraj meant independence from colonial power, but had the deeper implication of cultivating capacities for personal self-governance as opposed to relinquishing control of oneself to the state (there are echoes of Kant here). In Gandhi's view (as with Malinowski later in Freedom and Civilization), the only means to counterbalance the 'soulless' power of the state was to enrich practices of voluntary association; the foundational analogy being life as a fellow villager. Gandhi thus argued against those who thought that swaraj would be achieved simply by transferring power to an independent Indian government (1910). All this suggests that the meaning of swaraj was already open for discussion well before independence. Either way, the matter turns out to be more complicated since the prefix sva in swaraj, though it suggests a personal pronoun, does not translate directly as 'self' - instead it is closer to 'own', hence its bifurcating use to mean both 'self' and 'home'. Vaidyanathan has therefore argued that, rather than 'self-rule', a truer translation of swaraj into English may be 'proper rule' which paradoxically has the potential to mean the opposite of autonomy (Vaidyanathan 1989). Note that autos in ancient Greek means 'self' but also 'same': Orlando Patterson has argued that the Greek understanding of 'self' and hence the idea of self-governance evolved dialectically from the distinction between slaves who were ruled, and citizens who ruled themselves (1991).

During Lino e Silva's fieldwork in one of the largest Brazilian slums (see chapter 7) his interlocutors almost never used the word 'freedom' in their daily lives. Since the ethnography was conducted in Portuguese, people spoke of 'liberdade', 'liberada', 'libertação' and not of 'freedom'. This may sound obvious, but many difficulties arise from it. Peter Gow (see chapter 6) notes the various candidates for translating what we might take to be an antonym of 'freedom'-'slavery'- 
amongst the Piro. Each of these meanings has valences, including notions of kinship affiliation, absent from the liberal understanding of slavery, he argues. Hideko Matsui picks up this problem from a different angle when she discusses the political and cultural repercussions of transliterating the Dutch word 'vrijheid' ('furaiheido') in Japanese 'without explaining the meaning of the original word' (see chapter 2). Even in English, as we have pointed out in this introduction, and as Nigel Rapport explores further (chapter 1), there are subtle incommensurabilities between, and thus distinctive semantic potentials for deploying, words like 'liberty' and 'freedom'. Whereas, in other languages, such as Portuguese, the challenge is the opposite: 'liberdade' could mean both 'liberty' and 'freedom'.

Any exercise of translation is unavoidably bound to indeterminacy. In fact, the theory of the indeterminacy of translation could help to further our ontological understanding of freedom. If we accept the position defended by Williard von Quine (1981), who argues that no translation is ever absolutely determined, the awareness that 'freedom' is not, for example, isomorphic with 'liberdade', or 'living this way' or even 'furaiheido' seems to become both clearer and also less problematic. Quine (ibid: 23) explains that indeterminacy of translation reflects the fact that 'two conflicting manuals of translation can both do justice to all dispositions of behavior, and that, in such case, there is no fact of the matter of which manual is right.' To that extent, 'freedom' is understood as an imprecise translation of 'liberdade'. The expectation, however, is that the replication of ethnographic instances in which the word 'liberdade' is put into practice in 'the field' may help to reduce some of the unavoidable indetermination of translation, so that an equivalence between the two terms can be more precisely delineated by each one of us, even if never completely resolved. Quine (ibid: 20) reminds us: 'The translation adopted arrests the free-floating reference of the alien terms only relatively to the free-floating reference of our own terms, by linking the two'.

The issue of translation preoccupies Caroline Humphrey in her writing on freedom. In 2007, Humphrey published an essay entitled 'Alternative Freedoms', which is a more current example of an anthropology of freedom. The fact that the American Philosophical Society awarded a prestigious prize to Humphrey for that essay is an indication of how important an anthropological approach to the theme of freedom could be for other disciplines. Interestingly, though, in her text Humphrey intentionally brackets off discussions regarding what philosophers have to say about freedom. Instead, she emphasizes how some people in Russia, with whom she had been working for years, 
referred to ideas similar to freedom. In Humphrey's (2007: 1) words: 'I want to use our word 'freedom' - whose multiple meanings will be implicit and left to your imaginations - to elicit, as it were, a range of ideas held in Russia.' However, the author does not really address in depth the problem of how meanings left to imagination could still elicit certain ideas that the Russians held on freedom.

In ethnographic studies regarding the topic of freedom in the lives of 'others', if the researcher proposes to grasp the existence of freedom as an object of ethnographic research, the conditions of possibility for such an object to exist need to be somehow established. In most cases, researchers are happy to assume that a given meaning of freedom (often not spelled out) is a good enough theoretical basis to be deployed in their search for 'freedom' (or 'autonomy') in the research setting. For example, say an anthropologist has the following in mind: 'freedom means $X^{\prime}$. Having at some point experienced this specific ' $X$ ' meaning of freedom, during research, the ethnographer proceeds onward to look for objects similar enough to what the meaning ' $X$ ' accepts as 'freedom'. Importantly, this is done independently of whether the others involved would necessarily call ' $X$ ' freedom, or not. Therefore, having encountered certain 'freedoms' in the field whose existence was initially allowed by ' $X$ ', the anthropologist proceeds to finding out what linguistic sign would best refer to ' $X$ ' in the specific language.

The advantage of this strategy is clear. It addresses the issue of 'translation' in a straightforward manner: translation becomes a matter of finding an object whose existence is allowed by the imaginative range offered by ' $X$ ' and of finding which specific linguistic signifier is used to refer to that object. This approach remediates a situation in which some people could be argued to have no freedom if they do not have the word 'freedom' (or an assumed direct translation of it) in their language. The disadvantage, however, is that it assumes a priori certain meanings for freedom that are not just difficult to spell out, but if they were possible to spell out, they would reveal that those ' $X$ ' meanings attributed to freedom are often the ones that the anthropologist already knows, and not necessarily meanings created by the people with whom the ethnography has been conducted. In an extreme scenario we could end up with 'native' objects and signs for a freedom that could have more meaning as 'freedom' to people foreign to that context than to people in it. It seems at least possible that the reiteration of 'autonomy' in many settings may indicate a pre-theoretical assumption on the part of the anthropologist; but what, in turn, does that imply? Some of the assumptions involved seem to be directly connected to how the self or subjectivity is thought to be constituted and how freedom is expected to 
Freedom in Practice: Governance, Autonomy and Liberty in the Everyday

Moises Lino e Silva and Huon Wardle [PREPUBLICATION VERSION] (2016)

feature in this constitution.

\section{The subject of freedom}

As the last examples show, there are clear dangers in assuming too much about what people mean by the seemingly shared ideasfreedom, autonomy, liberty. Returning specifically to autonomy, firstly, the significance of 'self' - the 'auto-' in 'autonomy' - can be radically indeterminate across cultures when measured against a certain kind of Euro-American expectation. After all, ethnographic surveys and models of what a 'self' is offer something of a smorgasbord. To take one instructive case, Marriott has argued that the image of an island-like individual self in a sea of social activity often encountered in Western thought is largely alien to the mainstream of Indian culture where instead the view of what it means to be human is fundamentally sociocentric. Self is not here a causal force in its own right-it is not the selfpropelling soul or autokineton of Platonic philosophy-rather its consistency derives from the relations in which it is engaged. When the self becomes isolated from sustaining social relationships (by disease for example) it manifests this not in the form of a stripped down or bare individuality, but rather as a problematic 'dividuality' awaiting personal reintegration within the social matrix - the soul-body can only be made whole again through reconnection to others (1976). It turns out that this kind of relational view of the self is as widespread in the ethnographic literature as is the emphasis on autonomy - but perhaps it is equally as prone to problems of translation. Either way, social-holistic views of personhood and autonomy of this kind are often expressed in terms of bemusement with a Western philosophy of self that seems to imply:

a little man stuck in a person's head making all the decisions for that person. This little man cannot be shut off from outside. But, then, you wonder whether there is an even smaller man in the head of the little man, and so on and so forth (Li 2014).

Since the self, in this kind of view, is the force behind and terminus of its own autonomous planned actions, this can seem to set off a regressive search for the absolute source of this (seemingly paradoxical) self-causing self-identity - an infinitely reiterated homunculus pushing the cognitive levers of so-called 'free will'. The special philosophy of 'free will' has given a unique twist to much European and North American thought especially since the European Enlightenmentforegrounding a problem or conflict that seems either absent in other 
worldviews, or as presenting an illusion to be overcome, as in Buddhism where arrival at an experience of 'not-self' offers a spiritual alternative to a life of subjective striving and desire (Gowans 2003:25). Indeed, Buddhist practices of liberating the self from its indebtedness to past and future, ego and other, suggest something of a polarity with a Western eschatology that understands these relations as precisely constitutive of ethical 'free will', as we will see in this introduction.

As mentioned, the difficulty of disentangling 'freedom' from the philosophy of 'free will' probably gives one reason why anthropologists have preferred to talk about the 'autonomy' of the people they work with rather than their 'freedom'. Certainly, we cannot discuss freedom without exploring the concept of free will, but we will leave that issue for now picking it up later. Suffice it to say that, if we are to take autonomy to be something like a universally available idea, then we will have to cut loose from the assumption that autonomy and free will are in effect the same. Some idea of a self that goes its own way remains behind though. The evidence suggests that autonomy offers a broad if not consistent foundation for the much more historically and culturally specific concept of free will; but not the other way round. Nineteenth Century teleologists such as Hegel argued that 'free will' was a necessary intellectual outcome of the dialectical struggle for autonomy at the apex of which is the self-governance of the fully individuated human being within a state. The contemporary position has to be much less secure to say the least.

If the dimension of 'self' - the 'auto' in autonomy-is significantly indeterminate, so too inevitably is the notion of 'governance' - nomos, lawfulness - that is the second aspect of the word. The problem of 'lawfulness' or governance cannot appear in the same way for someone who considers their life to be self-caused as it does for one who understands their personal actions as an outgrowth, or fluxional expression, of custom or of social relations. Historically, the idea of selfgovernment seems often to emerge as a reaction to restrictions on following a traditional pathway which in turn gives rise to an assertion of positive autonomy or self-determination. Some of the social forces involved are captured in this description by Lowie of Plains Indian individualism:

The worst Crow insult was to tell a man that he had no relatives, for it meant that he was a social nobody subject to abuse. To a spirited lad this taunt, however, was a challenge: he could court spiritual blessings, distinguish himself in fighting, gain wealth, and ultimately shame his detractors (Lowie [1920]1954:124). 
It is not 'free will' that is being claimed here, though this might be implied, what is at issue is the reintegration of someone back into the mainstream of community life, which has been cut off in one direction, by way of other kinds of valued relationship. We can note, in this regard, that in Europe conflicts over religious autonomy were rife long before the liberal enlightenment analytic of existential freedom gained traction. For example, the 'antinomianism' of $16^{\text {th }}$ Century Protestants built on centuries of ideological struggle for religious self-governance vis-à-vis an incomprehensible, exclusive and socially distant church hierarchy.

We should expect to find then, despite the broad generality of the idea of autonomy, that the pragmatic contexts and meanings accompanying it will vary dramatically. To take one example, for the Papuan Kapauku, according to Pospisil, individual freedom is an all-important cultural idea and this extends into how the relationship between soul and body is constituted - for Kapauku soul and body are autonomous agents whose cooperative efforts bring about individuality in the full sense-neither can achieve this on its own. Soul can dream in an inert body, bodily action can continue even in the absence of awareness, but neither soul nor body is a fully conscious person except in coalition. If, though, soul and body fail to acknowledge each other's autonomy this will lead to sickness. Likewise if the individual is forced to work for others, or their movements are curtailed by being jailed, these restraints can cause fatal illness due to the body's resistance to compulsion and the effect of this bodily revolt on the soul (1978:84-88). The Kapauku have stood out in the ethnographic record as a small-scale society characterized by values (individualism, personal freedom, commercial competitiveness) more usually vaunted amongst business-people in grand-scale commercial settings. Despite this seeming cultural familiarity though, as Pospisil shows, the integration of autonomy into their other cosmological ideas is distinctive.

It is worth considering in this light that the relative 'autonomy' that a given person or community is able to claim offers a vital sign of how they are understood and valued by others around them. For example, this is what Pipyrou's (chapter 4) demonstrates through her research on conflicts generated by the imposition of multi-governance through civil society organizations in South Italy. The boundaries of this process of authorizing autonomy are, of course, constantly open to extension and contraction. In a landmark decision, in May 2015, a New York judge issued a writ of habeas corpus on two chimpanzees held at laboratories in a local university, Stony Brook. Initially at least, the judgement seemed 
Freedom in Practice: Governance, Autonomy and Liberty in the Everyday

Moises Lino e Silva and Huon Wardle [PREPUBLICATION VERSION] (2016)

to indicate willingness on the part of the judge to acknowledge arguments made by a group advocating 'Non-Human Rights' that the primates were 'autonomous and self-determining being[s]'. ${ }^{1}$ The debate involved is telling at many levels, not least because it seems to take for granted that everyone concerned knows what 'autonomy' means in practice and the only remaining question is how to extend this idea to 'non-humans'. As we have already observed, this is hardly the case since, while autonomy taken loosely has seemingly universal valence, its pragmatic and situational ramifications can be radically distinctive: so much so that what is viewed as a move toward autonomy in one situation can be quite literally sickening and soul-destroying in another. In Hind Swaraj, Gandhi argues that the large number of British women engaged in paid work, and likewise the contemporary suffragette movement, was indicative, not of the growing autonomy of women, but instead of a deep moral sickness and malaise in a British way of life that was, he suggests, bound to destroy itself (1909:24). It may be a necessary feature of any particular discourse of freedom that it forecloses as much as it opens.

Hence, we might say that, at least in most cultures that we are aware of, people seem to agree that autonomy is a valuable human (and nonhuman) good for those deemed to deserve it, but, both cross-culturally and it would seem intra-culturally too, there may be little agreement about what this good looks like in context, even less in practice.

\section{Possible freedoms}

What I am afraid of about humanism is that it presents a certain form of our ethics as a universal model for any kind of freedom. I think there are more secrets, more possible freedoms, and more inventions in our future than we can imagine in humanism as it is dogmatically represented on every side of the political rainbow: the Left, the Centre, the Right (Foucault 1988:15).

These comments by Foucault contain a degree of cryptic optimism as well as elements of a theory about the conditions for freedom, both of which ask to be delved into. Foucault takes it as self-evident that 'humanism' and ideas about 'freedom' are interconnected historically, but he proposes that freedom can also exist independently of humanism as we have known it up to now. There are more freedoms available to us than we currently imagine; either way, humanistic ethics in its current dogmatic version has perhaps outlived itself - other

\footnotetext{
1 'I've Won a Day in Court for Two Chimps' New Scientist May 11, 2015.
} 
frameworks for freedom can be invented. Sundering humanism from freedom, as he elaborates elsewhere, calls for a rethinking of the self and the techniques that go into creating it.

Freedom, if it is often used interchangeably with either autonomy or liberty, has resonances of its own. We have seen that freedom is often thought of technically as the ability to exercise 'free will'. As we also saw, this idea causes considerable confusion to those for whom it suggests an infinite regress: does the self have within it another agenta 'free will' that triggers its 'free' actions? If so, what is this 'free will' triggered by? And so on. At quite another level 'freedom', 'autonomy' and 'liberty' have different derivations and the differences in usage are suggestive. In English, autonomy indicates a capacity for self-rule, while the state of being 'free' - 'freedom' - suggests something else; not only action that goes unimpeded, but feelings and behaviour that are spirited, generous and whole-hearted. Cognate words including 'frank' and 'friendly' supply further insights, as do the old Norse word frja, to love, Old Saxon friohan, to court or woo, not to mention contemporary Dutch, vrijen, to woo or caress. There seem to be charismatic and enthusiastic qualities to being 'free' that are not so obvious when we refer to possessing 'autonomy', or 'liberty'.

Liberty, which derives from Latin liber, a free person, is rooted etymologically in the idea of growing amongst a people (IndoEuropean, leudh- to grow up; people; free, Shipley 1984:220). From this viewpoint liberties derive from growing with, and hence having rights in, a community. In this vein, Humphrey notes that svoboda, one of the Russian words translated as 'freedom' indexes a 'Svoi' or 'We' who are 'full members of the patriarchal and kin-based community' suggesting something more like the root meaning of 'liberty' than 'freedom' (2007:2). Like freedom and free, liberty has an adjectival form, liberal, but liberal and free have only limited semantic overlap in English. In the case of Liberty and autonomy the idea of regulation by norm or law is a necessary element of the definition, but this is not so with freedom. When, in The Social Contract, Rousseau defines true liberty as 'obedience to a law which we prescribe to ourselves' he might equally be defining autonomy: indeed, Kant turns Rousseau's view into his own logic of the 'autonomous will'. 'Autonomous' and 'free' correspond more closely in meaning than 'free' and 'liberal', but, as we have already seen, what they bring to mind is also subtly different too. 'Free', draws most directly on the image of a self that is able to do whatever it wants to the fullest extent, whole-heartedly. The notion of a kind of governance to which freedom corresponds is only a secondary consideration. It is 
precisely in relation to this indeterminacy of freedom that the philosophical problem of 'free will' arises.

As opposed to liberty or autonomy, then, in English usage at least, freedom is an unruly and, quite literally, underdetermined concept. Liberties, we can say, derive their meaning from participation in the life and growth of a community; they are 'taken' or enacted publicly with and against others whose status is thereby marked. We can note how in the $17^{\text {th }}$ Century 'liberal' was a term of abuse for persons who acted or spoke 'unrestrained by prudence or decorum' 2 -a meaning that has reappeared in contemporary American political discourse. Autonomy is as much a mode of self-discipline as it is a rejection of external rule; no doubt a potentially satisfying one when thought of in connection with ideas of personal maturation and the ability to think and act for oneself. There is clear commonsense meaning to freedom that seems to be rather too quickly ruled out of court by philosophers and other ethical theorists as naïve, namely 'doing and saying what I like'. Again, by this definition, the minimal description of freedom as 'acting without constraint' seems insufficient on closer inspection: freedom always implies a charismatic sense of subjective abundance, even love. Freedom is surely more than simply a lack, or an absence of, control. Either way, playing up these distinctions between liberty, autonomy and freedom should remind us, if nothing else, that these words can carry with them unconsidered implications even into the most carefully thought-through theoretical discourse. Distinctions like these, between some of the English valences of 'freedom' versus those of 'liberty' are taken up by Nigel Rapport in his discussion of the artist Stanley Spencer (chapter 1). A liberal society will make institutional space for individual freedom, even of the sometimes extreme imaginative types that Spencer instantiates, but 'freedom' in this analytical use is divided from 'liberty' in much the same way that the world as it exists for the imagining subject is divided from how it exists objectively, Rapport argues.

\section{The politics of 'free will'}

Hannah Arendt holds that we have St Augustine to blame for the special status of 'free will' in Western philosophy (1978). In his Confessions, Augustine sets up 'willing' as the dimension of self that unifies and organises 'being' and 'knowing' when the time comes to act in the world. Only because I will does the awareness of what I am and

\footnotetext{
${ }^{2}$ Cf. Oxford English Dictionary: 'Liberal', adjective \& noun, definition 3a.
} 
what I know take the shape of a unified self that acts definitively. Unlike God, a human self cannot know itself absolutely or transcendentally: forced to know the world in time, hence blinded from absolute truth, the self must depend on its free will to make its own path, for good or ill. Augustine arrives at this integral force of the will by distinguishing it from the 'heresy' of the manichees for whom the self was a chaotic battleground of spiritual forces. Precisely by emphasizing the conflict of the will with itself Augustine is able to make a unifying free will the crucial factor that demonstrates the integrity of the self. It is the self-evident conflict of willing - a soul that wills and nills at the same moment - that characterizes knowledge of the self as someone who judges how to act in time (Arendt 1978:84-110).

If Arendt is right, then Augustine has bequeathed, at least to Westerners, a truly multi-layered, three-dimensional epistemological conundrum. It may be much less easy than we think to extract the ingredients we don't like-to escape some of those humanist ideas about freedom that that Foucault refers to. Either way, Augustine's argument is further embedded in a much deeper and more widely ramifying set of cosmological assumptions about the place of human beings in the world-at the centre of which is a particular myth of origin. Here is how Fromm describes and analyses it:

The biblical myth of man's expulsion from Paradise... identifies the beginning of human history with an act of choice, but it puts all emphasis on the sinfulness of this first act of freedom... Man... acts against God's command, he breaks through the state of harmony with nature of which he is part... From the standpoint of the church... this is sin. From the standpoint of man, however, this is the beginning of human freedom... freeing himself from coercion... committing a sin is... the first human act (Fromm 1965:49-50).

For humans living in history (that is, acting in time), understanding the world begins with a singular choice, a free act, a fully human act, also the first sinful act because it defies the order of the cosmos. Freedom may suggest love, abundance and an enthusiastic state of indeterminacy, but, cosmologically speaking, free action is sin, defiance and ignorance. As Fromm argues, in Abrahamic doctrine, the relationship of divine order and human freedom is irretrievably paradoxical. Compare the above statement with one derived from anthropologist Paul Radin's fieldwork with a group of hunteragriculturalists, the Winnebago: 
Freedom in Practice: Governance, Autonomy and Liberty in the Everyday

Moises Lino e Silva and Huon Wardle [PREPUBLICATION VERSION] (2016)

The right... to freedom of expression [amongst the Winnebago] is never for a moment questioned.... Free expression of thought was the order of the day and was viewed as a purely private concern, system-mongering or a systematic theology, for instance, was quite useless... It remained the expression of a particular man or, at best, of a particular group ([1927]1957:57)

As Radin argues, for the Winnebago at least, personally held thoughts and theories posed no particular problem to community life. There were in this setting no book-based codes of ethics against which freely formulated ideas could or should be judged. Either way, personally held interpretations had little effect on the fundamental needs and flows of social life. Freedom was taken for granted, but 'Free will' did not here arise as a distinct question because thinking and acting did not happen in the shadow of the Word of God. This, he noted, was in stark contrast to those literate cultural settings where the written word often takes on the aspect of an absolute objectivity against which subjectively held thoughts and actions must be measured and judged-with a resultant 'distortion in our whole psychic life' (Radin 1957:61). In Augustine's and others' accounts of the experience of monotheism, the question, theologically at least, becomes one of how to conform out of the finitude of one's own life to the divine word given how little knowledge of God's intention is subjectively available. It should be noted that while freedom of thought and a high emphasis on autonomy in people of the Plains like the Winnebago, individual actions were policed where they posed a threat to communal life - to the food supply in particular (cf. Lowie 1954:126).

As Fortes shows in his analyses of the ancestor-worshipping Tallensi, the key psychological conundrums involved in the notion of free will are not in any absolute way confined to monotheistic cultures. Tallensi eldest sons worry constantly about whether their decisions and actions are in conformity with the will of their male ancestors (1959). However, as Gellner likewise indicates, it has been in monotheistic settingswhere the holy book and the sword combine in a single mode of domination - that the paradoxical qualities of 'free will' have taken on a particularly hard political outline (1988). And, as Chris Kelty points out, this writing of free-will into the source-code of cultural life continues quite literally into the Western present (see chapter 8). Echoing Gellner's account, Edmund Leach argues that in small-scale societies like the Kapauku, the individual can sometimes be 'moderately free because his rulers are incompetent rather than because they are benevolent' (1963:81). This self-confessedly cynical view, which assumes that the rules of society are imposed not agreed, is nonetheless 
of some relevance in thinking about Radin's case study. If 'freedom of expression' amongst the Winnebago changes little about the social situation - that is, if it makes no authentic difference to how people lead their social lives - then is it really freedom at all? Malinowski (1947) reserves some of his harshest criticism for Boas who, along somewhat similar lines, proposes that freedom 'is a concept that has meaning only in a subjective sense. A person who is in complete harmony with his culture feels free. He accepts voluntarily the demands made up on him'. By that standard, Malinowski responds, the person who has fully incorporated 'Nazi indoctrination' is free.

Free will, as commentators like Foucault, and indeed many others, have pointed out, describes a special historical configuration of psychological and epistemological concerns. Even so, it is difficult, looking out at the world from within the field where those concerns operate, not to question the validity of other understandings of freedom. If someone seems to be absent of a kind of constraint that I feel in my life (as when Radin describes the Winnebago as feeling no restriction on expressing their diverse personal worldviews), does that mean that they are positively free (see Berlin 1958), or am I simply projecting a concern of my own onto their way of life? Malinowski confronts (or perhaps avoids) the same problem when he argues that purely subjective understandings of freedom, ones based on how or whether people imagine themselves to free or not, can never answer the question of the social value of freedom. Freedom for Malinowski is an objective element of, and an increment in, customary social action; what people may or may not think about freedom is of little consequence compared to what they actually do, how, in other words, freedom is built into their patterns of social action.

Here we might respond, based on our previous discussion, that Malinowski is really talking less about 'freedom' than about 'liberty'. Indeed, Malinowski's view of freedom as a social 'surplus' available to people who share a common language, customs, laws and techniques fits exactly with the etymology of 'liberty', but rather less well with the unruly and charismatic concept, freedom. The degree to which midTwentieth Century social anthropologists thought that the subjective, imaginative or existential aspects of freedom were irrelevant or detrimental to their concerns is striking. Leach (1963) violently disagrees with Malinowski's functionalist view of freedom, but he is equally indifferent to how people might feel or think about their own freedoms; he is only interested in the socially objective side of the matter-freedom is relevant only as an objective political datum or symbol in a given social system. As suggested already, in this volume 
Freedom in Practice: Governance, Autonomy and Liberty in the Everyday

Moises Lino e Silva and Huon Wardle [PREPUBLICATION VERSION] (2016)

we tend to use 'liberty' to describe the public and objective aspect of freedom, but we also allow ourselves room to consider freedom in other ways; ways that Leach and Malinowski would like to rule out.

The problem of 'free will' continues to be a problem precisely because it falls between the subjective and the publicly verifiable dimensions of what it means to be a human being. Given the objectivity of divine law and individual's limited comprehension of the world, 'free will' comes into play as the ethical mode in which action may be understood either to conform to God's plan or diverge sinfully from it. 'Free will' is not the same as 'freedom'; it is a special theory of how human individuality plays out in a world where the rules must be somehow distinguished 'through a glass darkly'. The problem here is that since anthropologists in the phase of disciplinary consolidation tended to ignore subjective experience in favour of accounts centred on cultural or social pattern, the problems involved (falling as they do between the disciplinary stools of psychology and anthropology) have remained unexplored (Laidlaw 2014).

\section{Freedom between imagination and bodily action}

For years, I have dreamed of a liberated anthropology. By 'liberated' I mean free from... a systematic dehumanizing of the human subjects of study, regarding them as the bearers of an impersonal 'culture', or wax to be imprinted with 'cultural patterns', or as determined by social, cultural or social psychological 'forces', 'variables', or 'pressures' of various kinds. Victor Turner (1979:60)

Certainly, some anthropologists have reacted strongly against the idea that only the objective cultural pattern counts when understanding social life; as Victor Turner does in this quote, invoking the concept of a 'liberated anthropology'. Turner argues here for re-envisaging social life as an unfolding improvisatory drama rather than as a closed system, a drama in which subjective free-play is crucial. But, though the countermodernist ideas that Turner talks about have been much discussed in anthropology, it is not obvious that they have led to a considerably greater critical understanding of the interrelationship between 'cultural patterns' and freedom as a cohere in self experience.

Are there ways of understanding these two aspects as part of the same picture? Or, are we condemned always to divide the subjective from the objective, social forces from subjectivity, perhaps inevitably reducing 
one to the other? When we talk about our 'sense of freedom', i.e. when we dive into the existential experiencing of freedom in the way that Malinowski wanted to rule out, we find that this sense is closely bundled with other features of consciousness more broadly. In particular our feelings of freedom seem to be bound up with the special relation between reflectively imagining the world and existing bodily and materially in it. Lev Vygotsky gives an illustration of this in his discussion of the play-learning of children:

The difference between the practical intelligence of children and animals is that children are capable of reconstructing their perception and thus freeing themselves from the given structure of the field (1978:35, our italics)

It is precisely what happens during and immediately after this moment of imaginative abstraction that indicates the stage of learning that the child has reached. Vygotsky refers to this as the zone of 'proximal development' 1978:86. He is working with a classic definition of play as an imaginative activity, where imagination is defined as the capacity to re-present something in the mind which is at that moment absent to the senses. Given what we now know about play amongst animals we may question the special status Vygotsky awards human infants in this area. However, for the purposes of this discussion, Vygotsky is making an important link between the feeling and meaning of freedom and the capacity to imagine. Play involves children in the important imaginative work of 'freeing themselves' from reality in order to remake it in their own minds. In this way learning entails a crucial kind of freedom. For children, play, manipulation of the object world is also freedom from material constraints - the resistance the world presents as a 'given structure'.

We will return to how 'freedom' is like 'play' later. For now, we can note that this insight into the role of freedom in subjective experiencing takes us in a very different direction to the view (or absence of view) provided by classic anthropology that Turner highlighted. The special analytical status that Vygotsky gives to freedom in combination with imagining is also present in a widely held understanding that the most easily available kind of freedom takes the form of escape into the imagination. This is the purely subjective freedom that Malinowski dismisses; but what if imagination has a crucial role in enabling the public 'liberties' that he thought were truly important? Once we look at certain kinds of ethnographic material through this lens we may find that the processual triad that Vygotsky highlights-given reality, 
imaginative freedom, reconstruction of reality - gives us vital clues for understanding not only freedom, but also liberty and autonomy.

In order to illustrate the interpretive difficulties involved, we can take here a classic though complicated case presented to us by Maurice Leenhardt. In his ethnological work, Do Kamo, Leenhardt argues that the Canaques he lived with during the 1900s did not understand human individuality in the way Europeans generally did (Leenhardt [1947]1979). In particular, somewhat akin to Marriott's picture of an Indian type of 'dividual' and permeable self (see above), Canaques did not hold that selfhood implied the continuous and exclusive cohabitation of a mind with a body through time. To begin with, for them, there was no concept closely mapping what Westerners call a 'body'. Canaques nonetheless evidenced a notion of self that is familiar in some other respects. For example, Leenhardt informs us that when they told stories about themselves, rather than recalling spatiotemporally distant events back to their mind-body in the present moment, Canaque story-tellers would send their soul or ego out to the places where that event is located with their listeners as company. As far as the narrator-traveller is concerned, this all requires spatialnavigational capacities rather than skills of reconstructing dispersed temporal events. There is no problem of hysteresis or time-dependence for Canaques, then, though there is the danger of getting lost (1979:8485). Clearly Canaques understood the capacities of the self in an utterly different way to, say, Augustine for whom the human ego is thrown contingently into, and must reconstitute itself from, the passage of time (which is why the universality of 'free will' is so crucial as a reference point for him). However, this does not mean, in contrast, that Canaques had no ideas about freedom.

For all the complexity of Canaque concepts of human capacity, they seem to have held quite familiar ideas about the relationship between the ego who imagines a place for itself in the world versus the 'me' that is constrained by its own bodily presence for others. This becomes clearer when Leenhardt describes Canaque ideas about suicide:

For them suicide is a method of passing from the state of living to the state of $b a o-a$ state of invisibility and release from the body, where, liberated from the laws of this world, they can increase their strength tenfold and at the same time regain their dignity by satisfying their need for vengeance ([1947]1979:39 our italics).

What Leenhardt is indexing with the word 'body' in this sentence is a little unclear, because he has been explicit otherwise that Canaques do 
not have a unified understanding of the body. However, the general sense is plain; freedom most closely corresponds to removal of materialbodily constraints in order to give vent to certain kinds of desires of the soul-ego; suicide is specifically a liberation and way of achieving revenge. This is surely freedom as the ability to 'do what I want', albeit played out in an unfamiliar cosmological frame. Leenhardt goes on to point out that highly dramatized suicides are widely documented in Melanesian ethnography, but they did not represent a death wish as a Western reader might have it, because, again, Canaques did not understand death to mean an irretrievable end of life, more a personal sea change. In this Canaque drama, the soul is pitted against the material constraints of its embodied presence in the world and the value this has for others. Suicide is an escape by the imagining ego from its current material presentation: it involves a loss of bodily presence, but importantly also a renunciation of accountability to others. There are important clues here, it would seem, to what might be a primary type of imagined freedom.

The constraints which face the self may vary, but this seemingly primary freedom is the thought that the self can remove or evade those constraints, even at the risk of losing its own bodily connection to the situation. Arendt points to part of a dialogue between Socrates and Callicles in the Gorgias that has a significant resonance with this Canaque view. Discussing the proposition that it is 'better to be wronged than to do wrong'. Callicles contends according to the contemporary public norms that 'to suffer wrong is not the part of a man at all, but that of a slave'. In contrast, Socrates' puts forward the view that:

It would be better for me that my lyre or a chorus that I directed should be out of tune and loud with discord, and that multitudes of men should disagree with me rather than that I, being one, should be out of harmony with myself and contradict me (in Arendt1978:181).

In other words, whether a person is correctly acting the part of 'man' or 'slave' is of little importance compared to the contradictions that appear in one's understanding of oneself; this difference cannot be resolved simply by doing what is publicly expected. Socrates points to the difference between the mores that operate in the conduct of public life versus how the mind orients itself in its own situation. Hence, whatever liberties or constraints present themselves in the public arena, there is still the freedom of the mind to think otherwise. When Socrates talks of 'being one' he is, Arendt argues, contrasting this imaginative awareness 
against the 'chorus' of multiplying relationships the self finds itself caught up in-including the ramifying relationships of slave and master that Callicles refers to. Only by escaping back into conscious reflection can the self reconstruct the given structure of its field of action as something meaningful for its own life. Socrates is, then, demanding a special kind of freedom or autonomy for thought itself.

This kind of capacity for escape into reflective awareness-and concomitantly the freedom that consciousness feels vis-à-vis its existence for others in a publicly shared reality-seems to provide at least one fundamental analogy for freedom and autonomy in general. Georges Devereux, the psychoanalyst and anthropologist, indexes a strong corollary for this when he talks of 'the trauma of the unresponsiveness of matter'. He gives the example of Hopi mourners slapping the dead and accusing them of having died on purpose to grieve their survivors (1967:33). The soul is here understood as having maliciously used its subjective freedom or autonomy to leave the world where it should be accountable to those around it. This calls to mind other examples when people deliberately absent themselves, as when a child plays 'peekaboo'. The logic is not only close to that presented by the egoistic suicide of the Canaques, or Kapauku ideas about the mutual autonomy of soul and body, it reiterates the fundamental issue that consciousness is aware of a kind of freedom in its own thoughts, desires etc. that is in contrast to the relative unresponsiveness it encounters as a bodily presence in the material world. The words of a young American to Fred Alford point once more to this fissure:

'My cubicle at work is like a jail cell. My boss is a tyrant. But in a way it doesn't matter. I can think what I want about him, about work, about anything. In my mind I'm free.'

Do you ever wish you were a little less free in your mind, and a little freer at work? I asked.

'I never thought of it that way,' replied Sandra. 'One doesn't really have much to do with the other, does it?' (Alford 2005:14)

Recognising this kind of subjective freedom certainly does not contradict Malinowski's view that liberties are more than mere thoughtstuff; for freedom to correspond to something actual we must have freedoms, or lack them, in our lives in the world, not merely in our ruminations or imaginings. However, perhaps Vygotsky provides us with the factor that links the two sides of this impasse. Sure enough, the ruminative freedom of the Canaque, or of cubicle worker Sandra, to escape out of their material circumstances into the unconstrained life of the soul or ego is a recognizable, if a one-sided, freedom; but what of 
the freedom the child experiences as it plays, who steps out of the 'given structure of the field' in order to reorder, and then re-enter, that field? In this case the freedom has both a reflective escapist side and an intentional active one-freedom here presents itself not only in the act of reimagining the perceptual field, but also as an effect in the world, a change to the world. And this is not just a useful description of the role of freedom in childhood play-learning but also of the effects of imagination-led action in general: there can exist a productive relationship between imagined freedoms and practicably attainable liberties. But it must be admitted that this relationship sound a lot like the dialectics of 'free will'.

\section{Free-play: Freedom and Play}

Play is simultaneously liberty and invention, fantasy and discipline.

(Roger Caillois 2001)

If we are asked 'what does freedom feel like?' we may well find great difficult in giving any kind of definitive answer. If we were pressed we might reach for a suitable analogy - freedom is like 'driving fast... no one else around', 'the sensation of flying or falling in love', 'being some other better person while remaining yourself', 'mastering a set of difficulties one by one'. The metaphors involved seem inadequate and excessively diverse; sceptics regarding freedom might wonder if, as Levi-Strauss claimed sarcastically for the Polynesian concepts mana or hau, whether 'freedom' might be 'a mystification' - 'an effect quite often produced in the mind of ethnographers by indigenous people' (1987:47). However, it is also noteworthy that the images we tend to conjure up for freedom have something in common with how we describe play behaviour. Just as Caillois separates play into 'vertiginous', 'aleatory', 'mimetic' and 'competitive', so too feelings of freedom seem to be distinguishable along rather similar lines (Caillois 2001).

Discussing Vygotsky's ideas we have already mentioned play as a situation where freedom seems instrinsic. The connection can be taken further. While play produces a kind of order insofar as it 'marks itself off from the course of the natural process', Huizinga argues, play is nonetheless 'free, [it] is in fact freedom' (1949:8). Freedom, like play, takes on its concreteness vis-à-vis the unresponsiveness of everyday life against which it creates its own field and the meaning of freedom 
acquires specificity as a kind of play. Perhaps as Huizinga argues, then, what we mean by freedom and play is not simply analogous but identical-perhaps freedom is play? Even if this turns out to be a flawed view, it is worth probing further for the insights we may gain.

Consider, for instance, how Meyer Fortes describes the play behaviour of children in Taleland, Northern Ghana. Their play reflects the cattleherding and agricultural lifestyle: it involves, for example, making a cattle kraal out of dust, with twigs for a pen and locusts for cattle; or setting up an ancestor shrine out of a pile of mud with a pot shard for the hoe that is a crucial element in the 'real' shrine. For Tallensi girls and boys play is education; children play at, reorganize and integrate diverse adult behaviours and meanings until finally they have themselves become competent adults in their own right and the activities involved have acquired serious consequences. There is great attentiveness to the rules of adult life but without the adult emphasis on a necessary and absolute order. In their play children rehearse the 'interests, skills and obligations' presented to them by the world of adults, creating 'experiments in social living without having to pay the penalty for mistakes' (1976:475). What is key here is the capacity to experiment without penalty: if we look at the descriptions of freedom that Malinowski arrives at in Freedom and Civilization then that definition would fit well. Again, perhaps freedom is simply play by another name.

The freedom of play is paradoxical because the freedom to play depends on principles governing a reality that truly exists outside the parameters of the playworld-the cattle kraals of Tallensi children's imagination are free creations, but actually existing cattle kraals are the products of serious work whose parameters and consequences are welldefined. Gregory Bateson illustrates the paradox at the heart of play with a case of two dogs at sport where one plays at biting, without actually biting, the other. '[T]he actions of 'play' are related to, or denote, other actions of 'not play', he proposes (1976:121), but how can reality divide itself 'play' and 'not play' forms which are nevertheless co-dependent?' Bateson's answer lies in cognitive awareness of the difference between 'map' and 'territory'. Dogs at play, like human beings, have varying levels of reflective awareness concerning the difference between how their thoughts map the world versus how the world is in itself. Between biting and not biting a third option-playing at biting-offers an alternative; but one that can only exist in the gap between map an territory. Free-play thus appears as a space of its own in between how the world is experienced and how it can be imagined. 
Similarly, according to Huizinga, in its concreteness, freedom is key in play and freedom itself manifests as play. This implies that the limits of freedom are the limits of the field or frame of play behaviour. And yet, as Huizinga argues - Fortes claims this too-there is no type of serious activity that has not been formulated initially in the form of play-we arrive at our notions of the serious, the obligatory and rule-governed at least initially by way of free-play, free association. This means that we experience freedom regarding binding social obligations before we adopt those obligations as a serious fact of life. For example, we experience the correct practice of gender roles or scholastic codes first as a kind of freely enacted play, then as existential facts. Those who have arrived in the world of adult seriousness may, on this account, dip out of the code of quotidian reality occasionally by way of various types of sociability, game, or fantasy each of which has its own arena, rules of play and feeling of freedom. From this angle we can see how the discourse of freedom can differ from the experience of freedom rather as playing differs from the rules or frame provided for the game.

Pierre Clastres provides an example of this in his discussion of the solitary nighttime singing of men who hunt in Aché (Guayaki) society. In a setting which was particularly dependent on hunting for a livelihood, Aché placed a number of obligations on huntsmen including the fact that they must never consume their own catch, and that they must share a wife. For the group as a whole, the rules promulgated autonomy and constant reciprocity-all captured game being distributed within the group, no individual could stand out above others or against the community. However, Clastres notes that the hunters songs suggested a rebellion against this, an assertion of individual freedom: 'I am a great hunter' they would sing, 'I am in the habit of killing with my arrows, I am a powerful nature incensed and aggressive... Cho, cho cho (me, me, me)' (1977:94). For Clastres the parameters of nighttime song temporarily allowed a mode of absolute individualism to appear in a society where the imperative to exchange is otherwise omnipresent:

Thus the song of the hunter... provides a refuge in which to experience the freedom of his solitude. That is why, once night has fallen, each man takes possession of the realm that is his own preserve, where, at peace with himself, at last he can dream through his words the impossible 'talk with oneself'... The same man exists, then, as a pure relation in the sphere of exchange of goods and women, and as a monad, so to speak in the sphere of language. It is through song that he comes to consciousness of himself as an $I$ and thereby gains the legitimate usage of that 
personal pronoun. The man exists for himself in and through his personal song: I sing, therefore I am (1977:102-103).

The delimited character of this special songworld that Aché men enter at a certain time of day, and the type of personal catharsis it foregrounds shows Clastres that ultimately the freedom involved is limited; finally these Aché men 'cannot but respect the rules of the social game', he argues (1977:103). Clastres does not give us any further indication of how Aché men imagined things, so we have little means to judge whether in singing they were indeed conforming with the 'rules of the social game', or the extent to which the songs may have constituted a claim, as Sandra put it, that 'in my mind I am free'.

Clastres' description suggests, amongst other things, a characteristic urge in mid-twentieth century social anthropology (already described here) toward seeing society as a totality regarding which the human self is a part. At the same time he also notes the urge toward individual freedom as something perhaps natural, certainly inevitable given the particular social forces and conflicts at work. This, we should remind ourselves, is the view of the social that Victor wished to escape from when he argued against anthropology's tendency to regard human subjects of study as bearers of an impersonal 'culture'... determined by social, cultural or social psychological 'forces', 'variables', or 'pressures' of various kinds'. For Turner freedom is crucial since social life is not actually systematic (however much people may believe this is the case) but is rather the expression of constant improvisation by particular actors always trying out which symbols they will make use of, how they will weight certain gestures, where they will place themselves on the stage of action, make use of certain kinds of material props, and so on.

A problem which may arise in our intuitive reaction to Turner's core metaphor-life is drama-is that, while it gives back the free-play of improvisation to people rather than viewing them as cut out parts of a social totality, the extension of the metaphor of drama melts the distinction between real world and play world - the living individual is now an actor playing a part in a theatrical representation, but a representation of what? In the dramaturgic description of social experience the difference freedom and rule-governed experience blurs. Comprehending the lives of others as a drama to some extent takes away with one hand (the reality principle) what it offers with the other (emotional significance). We may nonetheless agree on the ontogenetic status of freedom in this account - what was once the focus of free-play becomes something held to in all seriousness in the moment of willful 
action; improvisation is deployed toward an intentional and earnest construction of reality.

For all its usefulness in reintroducing the improvisatory and the playful back into a discussion of the social, what the metaphor 'life is a drama' obscures, then, is the dimension of wanting or willing in the making of reality. While from the outside the excited use of symbols and gestures in a given event may look like drama-if we are unaffected by its consequences-to the person involved that world is serious and consequential. It is the relativity of the symbols and gestures in relation to our point of view that makes it seem dramatic. It is notable, in this regard, that a recurrent element of ecstatic religion is precisely aimed at temporarily, or even permanently, muting the will. Aldous Huxley captures an aspect of this when he describes the experience of taking the hallucinogen mescalin. Everyday consciousness involves a narrowing and specifying of perception and worldview: mescalin enables an opening up of sensation; a freeing of perception from the self's willful drive to organize reality in a particular way:

Though the intellect remains unimpaired and though perception is enormously improved, the will suffers a profound change for the worse. The mescalin taker sees no reason for doing anything in particular and finds most of the causes for which, at ordinary times, he was prepared to act and suffer, profoundly uninteresting. He can't be bothered with them, for the good reason that he has better things to think about (1994:13).

These 'better things to think about' take the form of a greatly intensified awareness of how the world is qualitatively for itself before it has been filtered into ontological categories. For example, 'at ordinary times the eye concerns itself with such problems as Where?-How far?-How situated in relation to what?' Contrastingly, under the effects of mescalin 'space... lost its predominance. The mind was concerned, not with measures and locations, but with being and meaning' ([1954]1994: 9).

This is freedom of a distinct kind. As Huxley notes, it is the type of freedom that Henri Bergson discusses in Time and Free Will (1910) where, for example, in our contemplation of 'orangeness' we allow ourselves to escape from our preconception of 'orange': subjectively the quality is freed from the category; the world no longer appears as a preformed ontological assemblage and instead offers an unmediated array of qualities (1994:11). This is perceptual free-play, but unlike play in Vygotsky's or Fortes' description it is non-dialectical: in it the pure 
contemplativeness of an uncontained self blends with an unbounded world. There are suggestions here of Buddhist self-liberation and the practice of becoming 'no one' that Matsui describes for Muneyoshi Yanagi (chapter 2). Of course, this subjective state, or perhaps non-state, is also utterly different to the ego-assertive songs of freedom of Aché hunters whose motif is a willful 'me, me, me'. Here we might consider I.M. Lewis' observation that ecstasis has particular significance for people living under atomized or highly individualized conditions where it presents a release from a sense of isolation (1971). In contrast, Clastres describes Aché self-assertion as an episodic expression of individuality in a social field more generally marked by the absorption of ego within patterns of exchange. Finally what Huxley describes is also unlike the distinction that Sandra makes when she talks of being a 'slave' in her cubicle but 'free' in her own mind: the feeling of there being an inhibiting boundary between those two worlds - outer, bodily and inner, mental-is here no longer primary. At the same time, we may begin to notice a continuum at work in which 'freedom' takes on different signficances with regard to the organization of self and world at different moments and within distinct kinds of perceptual space.

When he analysed Tallensi play, Fortes did so teleologically in terms of the achievement of adulthood; but the contrast of childhood play and adult seriousness seems overstated in some ways. Even if we can agree what it is that 'ends' in adulthood, surely improvisation does not cease even there, because the experimentation regarding truth, seriousness and legality-absolute maturity-never finalizes itself. For Tallensi, while the knowledge of children was incomplete in relation to that of adults, adulthood was also incomplete in relation to the knowledge of the ancestors. The proximal arena of imagining and acting never stops changing in relation to self understanding, therefore improvisation as freeplay is always at work if for no other reason than that the living individual cannot know what the ancestors want.

\section{Freedom as common sense, freedom in social science}

Although Peter Loizos, for example, laments that for too long anthropology avoided the theme of freedom because the discipline was under 'the spell of Durkheim and Marx, and so preoccupied with the problems of whole cultures, rather than those of individuals' (in Barker 1995: 89), the theme of freedom, as we have seen, is not necessarily tied up to individuality. Even writing at a time when anthropology was almost exclusively group oriented, Leach (1963: 86) was nonetheless able to point out a key anthropological predicament: 'since the word 
freedom is a powerful symbol in the ideology of the Western world especially the American part of it - it is only natural that Western anthropologists should endeavor to demonstrate that Freedom is a value esteemed by the Noble Savage.' There is a hint of a larger problem here: an anthropology which endeavors to demonstrate that other people around the world esteem the same values that Westerners, particularly Americans, do, can only be considered problematic. However, at the same time, Fischer and Marcus (1986) may have a point when they argue that an anthropology historically rooted in the Western world cannot ignore its own conditions of possibility, and cannot afford to ignore what impact its own powerful symbols have when it comes to understanding life as lived by others.

Leach's suspicions regarding 'freedom' as a word that was no longer relevant for thinking about how human societies organized themselves reflect a concern with an inherited set of ideas about freedom which no longer seemed to plausibly fit the circumstances of post-war Europe and America. In contrast, for thinkers of the Enlightenment, like the Scottish philosopher Adam Ferguson, human freedom had been a selfevident truth made obvious in the diverse choices humans made with regard to their 'wants' and 'opinions' - their way of life. The contrast between an Amerindian living on the Orinoco versus a prince in a European palace made the multiplicity of the possible choices and freedoms abundantly clear.

The occupations of men, in every condition, bespeak their freedom of choice, their various opinions, and the multiplicity of wants by which they are urged... The tree which an American on the banks of the Oroonoko has chosen to climb for retreat, and the lodgment of his family, is to him a convenient dwelling. The sopha, the vaulted dome, and the colonnade, do not more effectually content their native inhabitant (Ferguson [1782]2011:10).

In the same vein, Kant defines what he called Pragmatic Anthropology as the study of what human beings 'make of themselves' as 'free-acting' beings. This type of inquiry he opposed to Physiological Anthropology, which consists of an exploration of what 'nature makes of the human being' (Kant [1798]2009:3). For Kant, as for other Enlightenment figures there is an aspect of being human that is physiologically given, but there is also an aspect that is subjectively made. In particular, Kant highlighted that the schemas and concepts we deploy to understand our own lives are significantly of our own making. It makes a difference to our living in the world which schemas and concepts we live by. 
Thus, we spontaneously fabricate some dimensions of our own lives; these acts of imaginative fabrication, though they do not absolutely alter reality as given, become, to adapt a phrase of Vygotsky, our zone of proximal freedom. One purpose of pragmatic anthropology as a kind of inquiry was, then, precisely to explore the extent and limits of human freedom in practice. In certain areas of social inquiry this view of freedom as the essence of growth and change in human groups has been retained: 'we can grow cultures' proposes the anthropologist Tom McFeat, 'which, by the way, is a very nice experience; there is a planting and a growth and a budding and harvesting; there seems to be death and new growth' (1974:xii).

However, in contrast to this optimistic view, when Fred Alford asked his young American informants what they understood by 'freedom' in the early 2000s they seemed, almost uniformly, to see this word as little more than a synonym for one kind of out-of-reach cultural formpower and money. To have money was to have freedom and vice versa. Freedom had little to do with the exercise of imagination toward shared tasks. Preeminently freedom was understood as an objective measure of the power to 'do what you want'; this, in turn, being quantified in money terms. Alford was dismayed at the degree to which, because they felt they had little absolute control over their circumstances, freedom had come to seem illusory to them.

Maybe money can't buy happiness, but money buys freedom. Freedom means having enough money to do what I want,' said one young woman...

Most talked in these terms. Freedom is not about being left alone by others; nor is freedom about such effete rights as free speech. Many disparaged the concept. Partly because they took it for granted, but also because it doesn't matter if you can say what you want if you can't do what you want (Alford 2005:1-2).

At first sight these responses seem reminiscent of Georg Simmel's observations on the kind of alienated freedom provoked by a mass society that demands little of the individual as a citizen:

If freedom swings to extremes; if the largest group... affords greater play to extreme formations and malformations of individualism, to misanthropic detachment, to baroque and moody life styles, to crass egoism - then this is merely the consequence of the wider group's requiring less of us, of its being less concerned with us, and thus of its lesser hindering of the full 
Freedom in Practice: Governance, Autonomy and Liberty in the Everyday

Moises Lino e Silva and Huon Wardle [PREPUBLICATION VERSION] (2016)

development even of perverse impulses (Simmel in Levine 1971:270-271).

But Alford's informants seem to have gone beyond this kind of alienated individualism: for them freedom is no longer understood as a direct expression of the individual's liveliness - a defiant 'acting out' in the face of an uninterested world. Rather, subjective action of even this kind has lost its meaning because it has become a dependent variable of one objectively determining factor - the availability of money. The logic here seems to run somewhat like this: if all opportunities can be priced on the market, then it follows that 'free choice' is simply a function of relative access to the medium of exchange: this is freedom understood as an 'opportunity cost' in the micro-economics of everyday life.

To what extent this kind of view reflects the actual effects of 'structural violence' or the influence of a Social Scientific devaluation of individual freedom during the Twentieth Century it is impossible to say, but undoubtedly the pessimism of Alford's informants reflects a stance that was mainstream for much of the latter part of that century. James Laidlaw (2002) argues that the lack of research on freedom in anthropology is mostly a consequence of the deep influence of Durkheimian social determinism on the discipline: 'Durkheim's social is effectively Immanuel Kant's notion of the moral law, with the allimportant change that the concept of human freedom, which was of course central for Kant, has been neatly excised from it' (Laidlaw 2002: 312). However, something equally interesting is the imprecision with which freedom is commonly debated, when it is debated in social science at all. Even though the social determination of individual choices could not be shown in any decisive way, social scientists nonetheless tended to hold to the idea that 'free choice' was incompatible with the idea of empirical causality in general and was hence an illusion:

In the social sciences... [m]any of our... propositions are only statistically true and hold good only within particular historical circumstances... If these conditions make trouble for us as social scientists, remember they are a great advantage to humanity, by leaving men the illusion of choice. I speak of the illusion because I myself believe that what each of us does is absolutely determined... The illusion of free will... is a vital illusion... The most amusing case is the Marxists, who theoretically believe in macroscopic laws... but who will not allow the laws alone to produce the result... (Homans 1967:103-104) 
George Homans determinism ('I myself believe'), like that of many other social scientists of this period up to the present, is riven with doubt and contradiction. Reading his bold claim now, we may ask, if life is indeed 'absolutely determined' what possible difference could upholding the 'illusion' of free choice make? What is the difference between this convoluted stance and the idea that how people act, based on their view of things, has tangible and freely achieved effects (not least for themselves)? As Bradley and Green had already argued in the previous century, perspectives like Homans' seem to stem from following the mistaken logic that since the act results from the agent, her agency must be the result of some previous act (1884); but all this does is to inject a hopeless degree of ambiguity into the word 'agent'.

'Beliefs' like Homans' persist even when (as Homans admits) we are unable (ever) to indicate a location of the cause for an act except in the imagination and motivation of the agent in question. Where Kant envisaged a study of what humans make of themselves out of their freedom, post-WWII social science viewed itself as on a parallel track to the physical sciences. Sociology and Social Anthropology were by this definition the study of what society makes of the human being. Epistemologically, there was simply no place in the mainstream academic division of labour for the kind of human-centred intellectual pursuit that Kant envisaged. Thus there came to be very little if any room for a discussion of freedom at all, except as a sign or artifact of a certain system of governance. Certain versions of Foucault (Foucault himself seems to have left the possibilities of freedom open) like that presented by Nikolas Rose in his book Governing the Soul, envisage freedom as a peculiar feature of how modern subjectivity is constructed. Moderns are, he argues:

'Obliged to be free... modern selves have become attached to the project of freedom, have come to live in terms of its identity, and to search for the means to enhance that autonomy through the application of expertise. In this matrix of power and freedom the modern self has been born' (Rose 1990: 258).

This all begs reflection on the multitude of cases already mentioned here of non-modern peoples for whom autonomy and freedom are also seemingly of the essence. Are all these cases merely secondary elaborations of the modern psychic complex directed outward? This seems far-fetched. The opposite case can be made; moderns - unlike say the Winnebago as described by Radin - often seem to see freedom not as an obvious fact connected to being human, but rather as something 
mostly contingent: from this kind of modern point of view freedom, though much talked about, freedom is rhetorically overplayed and is not of great relevance to life as lived. Perhaps Rose's critique points to another concern then: any particular definition of freedom can be seen as an attack against the limited range of human freedoms actually or practically available to moderns.

As Englund points out, attempts at defining freedom have paradoxical effects. 'what appears as freedom from one perspective can be mere trivia from another.' For him, though, 'a crucial issue is whether those who occupy the public sphere are prisoners of their particular perspective.' '[T]he obligation to rethink the promise of freedom is constant and riddled with moral, political and intellectual quandaries' (1996: 4). Discussing the nationalist discourse of liberation in Africa, he notes a series of shifts, from a focus on liberation from colonial powers into other, newer notions of freedom, such as a human rights based views. Changed discourses open but also close the circuit for defining freedom-'new freedoms entail new prisoners' (Englund 2006: 4). Rather than intrinsically free, modern individuals often describe themselves as suspended in webs of causation over which they have little ultimate control: any particular 'freedoms' they may possess seem minor if not trivial with regard to the grand social scheme. There may instead be an emphasis on deploying various tactics of establishing a more attractive position for the self in a social field that cannot in any absolute way be changed by 'free will'.

Considering different tactics that can bring freedom to the self, the positionality of the ethnographer also deserves profound scrutiny when it comes the production of anthropological knowledge. Would the privileged position of 'researcher' imply more freedom to anthropologists than the position of 'ethnographic subjects'? Or would the opposite be the case? Pipyrou (chapter 4), concerns herself exactly with the implications of her own positionality in relation to different civil society groups in South Italy. She invites us to reflect: 'How can data generated out of intimidation and fear, or when the researcher is completely out of control of the situation, be fairly assessed?' Perhaps, such a question becomes even more engaging because anthropologists more often than not conduct their work in contexts in which they assume a position of authority (and freedom) superior to others? Or would it just be that 'academic freedom' sometimes is taken for granted? Regardless of the exact answer, any anthropology of freedom needs to concern itself with the implications of asymmetric relations of authority and freedom in its own production. 


\section{Towards an ontological understanding of freedom}

Regarding the very pragmatic puzzles that ethnographic research into freedom presents, an ontological approach can prove helpful. Awareness of the existence of freedom seems often to start from the presence of a signifier of freedom in the concrete research context, extending from there into the various meanings that freedom acquires in daily use. In this sense, an anti-foundational metaphysics of freedom arises for the researcher, based on practical research needs, something that William James (1975) would possibly call a pragmatic metaphysics.

The historical focus of anthropology on the importance and precedence of meaning has left discussions over the ontological dimensions of the ethnographic enterprise somehow underexplored when it comes to freedom. Ethnography, as an empirical way of knowing, could be (and has recently become) much more attuned to ontological concerns. This offers a partial response to the problems that Derrida (1997) and others have identified with what has been called the the metaphysics of the logos'. Derrida argues that in logocentric metaphysics 'The word is (...) already a constituted unity' 'That the signified (...) is always already in the position of the signifier, is the apparently innocent proposition within which the metaphysics of the logos, of presence and consciousness, must reflect upon.' (Derrida 1997: 93) It is necessary to challenge this seemingly unavoidable unity of the word and to underline how the supposed precedence of meaning relies upon other concurrent qualities and imaginative connotations of freedom. As things stand, the ontological dimension of our understanding of freedom in daily life remains underexplored as long as we remain preoccupied with the word alone. As Laclau reminds us 'the signifiers being goes beyond its 'designated role' which is to signify. As anthropologists, we should also be concerned with 'the fact of signifiers having effects other than meaning effects' (in Sumic 2004). Beyond words there is the bodily-imaginative practice of life: hence our emphasis in the title of this volume on 'freedom in practice'.

What, then, finally, is the relationship between the word 'liberada' (as in 'travesti liberada' and 'liberty' or 'freedom' (Lino e Silva in chapter 7), or 'wayegreru' and 'slave' (Gow) as experiences of life? An important aim in any exploration of freedom from an anthropological perspective should be to understand what people with whom we share our enterprise, think and how they live freedom themselves. In order to reach an understanding of how freedom is experienced by an 'other' (beyond oneself), an ontological discussion about the basis for our 
understanding is surely desirable. Quoting Quine (1981: 2): 'Little can be done in the way of tracking thought processes except when we can put words to them. For something objective that we can get our teeth into we must go after the words.' In this sense, words, and language in general, can be used as a means to enter a variety of dimensions regarding the existence of freedom - beyond meaning. 'Freedom' as logos may index precisely the authorizing 'rule' that freedom as freeplay is intent on bending, extending, reshaping-or breaking. The terminology used-'liberty', 'freedom', 'autonomy' may, indeed, be being deployed to hide some other or further unvoiced proximal claim about, or potential for, being human (see Huon Wardle's discussion in chapter 3).

Regarding the apparent vagueness of a definition of freedom on ontological grounds, we argue that all specific individuatives tend to be vague. This seems to be a characteristic of words in general. For example, terms such as 'dog' or 'desk' are also very vague. Many different objects and qualities of object go under the name 'desk'. As Quine (1981: 13) reminds us, 'this is vagueness only of classification and not of existence.' The fact that the most varied different physical objects count as 'desks' is not a problem for the existence of desks. Equally, the fact that the most varied actions, concepts, and life events could come to be counted as instances of freedom, is not in itself a problem. Quite the contrary, this could be a remedy to some of the unwanted consequences that follow from restrictive semantic definitions of freedom, alongside the overbearing power that certain meanings of freedom tend to assume at the expense of others. Quine (1981) has famously argued that no translation can absolutely determine meaning, and that no metaphysical theory can exclusively determine existence. The ontological definition of freedom proposed here extends the hope that freedom may come to exist under a variety of understandings, that it can assume a wide variety of meanings, even various, conflicting and contradictory ones. From here we may gain access to the further 'possible freedoms' that Foucault refers to. Such a radical understanding of the complexities of freedom as lived experience can only be achieved when freedom has been liberated from the precedence of meaning itself. 
Freedom in Practice: Governance, Autonomy and Liberty in the Everyday Moises Lino e Silva and Huon Wardle [PREPUBLICATION VERSION] (2016)

\section{Bibliography}

Alford, C. (2005) Rethinking Freedom: Why Freedom Has Lost Its Meaning and What Can Be Done to Save It, New York: Palgrave Macmillan.

Arendt, H. (1978) The Life of the Mind, San Diego, CA: Harcourt Brace \& Co.

Barker, E. (1995) LSE on freedom, London: LSE Books.

Bateson, G. ([1972] 2000) Steps to an Ecology of Mind: Collected Essays in Anthropology, Psychiatry, Evolution, and Epistemology, Chicago, Illinois: University of Chicago Press.

Bergson, H. (1910) Time and Free Will, London: George Allen and Unwin.

Berlin, I. (1958) “Two Concepts of Liberty." In Isaiah Berlin Four Essays on Liberty, Oxford: Oxford University Press.

Bidney, D. (1963) The concept of freedom in anthropology, The Hague: Mouton.

Caillois, R. (2001) Man, Play and Games, Urbana: The University of Illinois Press.

Clastres, P. (1977) Society against the state: The leader as servant and the humane uses of power among the Indians of the Americas, New York: Urizen Books.

Derrida J. (1997) Of grammatology, Baltimore: Johns Hopkins University Press. 
Freedom in Practice: Governance, Autonomy and Liberty in the Everyday Moises Lino e Silva and Huon Wardle [PREPUBLICATION VERSION] (2016)

Englund H. (2006) Prisoners of freedom: human rights and the African poor, Berkeley: University of California Press.

Evans-Pritchard, E. (1940) The Nuer: A Description of the Modes of Livelihood and Political Institutions of a Nilotic People, Oxford: Clarendon Press.

Ferguson, A. (1782) Essay on the History of Civil Society, 5th edition, London: T. Cadell.

Marcus, G. and Fischer, J. (1986) Anthropology as cultural critique: an experimental moment in the human sciences, Chicago: University of Chicago Press.

Murphy, C. and Throop, J. (2010) Toward an Anthropology of the Will. California: Stanford University Press.

Fortes, M. (1959) Oedipus and Job in West Africa, Cambridge: Cambridge University Press.

Fortes, M. (1976) Social and psychological aspects of education in Taleland. In S. Bruner, A. Jolly, SC K. Sylva (Eds.), Play-its role in development and evolution, New York: Penguin.

Foucault, M. (1988) Technologies of the Self: A Seminar with Michel Foucault, Amherst: University of Massachusetts Press.

Fromm, E. (1965) Escape from Freedom, New York: Avon Books.

Gandhi, M. (1910) Hind Swaraj or Indian Home Rule, Pheonix, Natal: International Printing Press.

Gowans, C. (2003) Philosophy of the Budda, London: Routledge. 
Freedom in Practice: Governance, Autonomy and Liberty in the Everyday Moises Lino e Silva and Huon Wardle [PREPUBLICATION VERSION] (2016)

Hoebel, A. (1954) The Law of Primitive Man. Harvard, MA: Atheneum.

Homans, G. (1967) The Nature of Social Science, New York: Harcourt.

Huizinga, J. (1949) Homo Ludens, London: Routledge \& Kegan Paul.

Humphrey C. (2007) Alternative Freedoms, Proceedings of the American Philosophical Society, Vol. 151, no. 1. 1-10, Philadelphia.

Huxley, A. ([1954]1994) The Doors of Perception, Heaven and Hell, Glasgow: Harper Collins.

James, W. (1975) Pragmatism, Cambridge, MA: Harvard University Press.

Kaberry, P. (1939) Aboriginal Woman: Sacred and Profane, Philadelphia: The Blackstone Company.

Kant, I. ([1798]2009) Anthropology from a Pragmatic Point of View, Cambridge: Cambridge University Press.

Laidlaw, J. (2002) For an anthropology of ethics and freedom, Journal of the Royal

Anthropological Institute 8/2: 311-332.

Laidlaw, J. (2014) The Subject of Virtue: An Anthropology of Ethics and Freedom, Cambridge: Cambridge University Press.

Leach, E. (1963) Law as a Condition of Freedom. In D. Bidney, The Concept of Freedom in Anthropology, The Hague: Mouton \& Co.

Leenhardt, M. ([1947]1979) Do Kamo: Person and Myth in the Melanesian World, Chicago: University of Chicago Press. 
Freedom in Practice: Governance, Autonomy and Liberty in the Everyday Moises Lino e Silva and Huon Wardle [PREPUBLICATION VERSION] (2016)

Lewis, I. (1971) Ecstatic Religion: A Study of Shamanism and Spirit Possession, London: Penguin.

Li, C. (2014) The Confucian Conception of Freedom Philosophy East $\mathcal{E}$ West 64/4: 902-919.

Lowie, R. (1954) Indians of the Plains, New York: The Natural History Press.

Malinowski, B. (1947) Freedom and civilization, London: George Allen \& Unwin.

Marriott, M. (1976) Hindu transactions: diversity without dualism. In B. Kapferer (ed.) Transaction and Meaning, Philadelphia: ASA Monographs.

McFeat, T. (1974) Small-group cultures, New York: Pergamon Press.

Myers, F. (1992) Pintupi Country, Pintupi Self, Berkeley: University of California Press.

Oksala, J. (2005) Foucault on freedom, Cambridge: Cambridge University Press.

Overing, J. and Passes, A. (2000) Anthropology of Love and Anger: the aesthetics of conviviality in native South America, London: Routledge. Quine, W. (1981) Theories and Things, Cambridge: Harvard University Press.

Patterson, O. (1991) Freedom in the making of Western culture, New York: Basic Books.

Pospisil, L. (1978) The Kapauku Papuans of West New Guinea, Boston: Holt, Rinehart, and Winston. 
Freedom in Practice: Governance, Autonomy and Liberty in the Everyday Moises Lino e Silva and Huon Wardle [PREPUBLICATION VERSION] (2016)

Radin, P. ([1927] 1957) Primitive Man as Philosopher, 2d ed., rev. New York: Dover.

Richards, A. (1963) Freedom, Communications, and Transport. In D. Bidney, The Concept of Freedom in Anthropology, The Hague: Mouton \& Co.

Rose, N. (1990) Governing the Soul: The Shaping of the Private Self, London: Free Association Books.

Rose, N. (1999) Powers of Freedom: Reframing Political Thought, Cambridge: Cambridge University Press.

Rousseau, J. ([1762] 1782) The Social Contract or Principles of Political Right, Translated 1782 by G. D. H. Cole, public domain.

Shore, C. and Wright, S. (1997) Anthropology of Policy: Perspectives on Governance and Power, London: Routledge.

Simmel, G. in Levine, D. (1971) Georg Simmel on Individuality and Social Forms, Chicago: University of Chicago Press.

Sumic, J. (2004) "Anachronism of Emancipation or Fidelity to Politics", in Laclau: A Critical Reader, Critchley, S. and Marchart, O. Eds., London: Routledge

Turner, W. (1979) Process, Performance and Pilgrimage, New Delhi: Concept Publishing Company.

Vaidyanathan, T. (1989) Authority and Identity in India, Diogenes 118/4:147-169. 
Freedom in Practice: Governance, Autonomy and Liberty in the Everyday Moises Lino e Silva and Huon Wardle [PREPUBLICATION VERSION] (2016)

Vygotsky, L. (1978a) Mind and Society, Cambridge, MA: Harvard University Press. 